\title{
O preconceito econômico-social na percepção de estudantes de odontologia: uma perspectiva crítica
}

\author{
Celso Zilbovicius ${ }^{1}$ \\ Leonardo Carnut ${ }^{2}$ \\ Tarsila Teixeira Vilhena Lopes ${ }^{3}$
}

\begin{abstract}
RESUMO
Este estudo teve como objetivo compreender a percepção dos graduandos de odontologia sobre os conteúdos relativos ao preconceito econômicosocial e sua relação com a saúde. Para isso, realizou-se uma pesquisaação pedagógica, crítico-colaborativa, com graduandos do $1^{\circ}$ ano da Faculdade de Odontologia da Universidade São Paulo, Campus Capital, em 2016. Para fins analítico-interpretativos, optou-se pela análise de conteúdo clássica, tomando-se como unidade textual as sentenças/proposições dispostas nos textos e para interpretação das percepções utilizou-se a matriz marxista. Foram construídas 18 categorias que sintetizam as percepções sobre o tema. As percepções sobre 'as doenças, independente de qual lado atingem, são motivos de estigmas e preconceitos' e 'os preconceitos socioeconômicos e racial estão conectados' foram as mais presentes na percepção deste grupo. Ao final, compreendeu-se que as percepções sobre o preconceito econômico-social é plural e contraditória, com momentos de reprodução e crítica do instituído, inclusive sobre o próprio papel dos estudantes nesse processo.
\end{abstract}

PALAVRAS-CHAVE: Ensino. Educação em odontologia. Ciências sociais. Pesquisa qualitativa. Preconceito.

\footnotetext{
${ }^{1}$ Professor Doutor da Faculdade de Odontologia da Universidade de São Paulo. Universidade de São Paulo, Campus Capital, São Paulo, Brasil. https://orcid.org/0000-0002-0780-8120. czilbo@usp.br.

${ }^{2}$ Professor Adjunto do Centro de Desenvolvimento de Ensino Superior em Saúde. Universidade Federal de São Paulo, Campus Capital, São Paulo, Brasil. https://orcid.org/0000-0001-6415-6977.leonardo.carnut@ gmail.com

${ }^{3}$ Mestre em Gestão da Clínica. Universidade Federal de São Carlos, Campus São Carlos, São Paulo, Brasil. https://orcid.org/0000-0002-5191-9717.tarsilatvlopes@gmail.com
} 
The Socioeconomical Prejudice in the Perception of Dentistry

Students: a Critical Perspective

\begin{abstract}
This study aimed to understand the perception of undergraduate dentistry about the contents of social-economic prejudice and its relation to health. For this, a collaborative, pedagogical action research was carried out with undergraduates of the School of Dentistry at the University of São Paulo, Campus Capital, in 2016. For analyticinterpretive purposes, we opted for the classical content analysis, taking as a textual unit the propositions and using the marxist matrix for the interpretation of perceptions. We constructed 18 categories that synthesized the perceptions about the subject. Perceptions about 'diseases, regardless of which side they reach, are grounds for stigma and prejudice' and 'socioeconomic and racial prejudices are connected' were the most present in the perception of this group. It was understood that the perceptions about the socio-economic prejudice are plural and contradictory, with moments of reproduction and criticism of the instituted, including about the students' own role in this process.
\end{abstract}

KEYWORDS: Teaching. Dental education. Social science. Qualitative research. Prejudice.

\title{
Introdução
}

A percepção moderna de 'preconceito econômico-social' deriva do desenvolvimento da ideologia burguesa, já anunciada por Marx e Engels no Manifesto do Partido Comunista (2007, p. 44) quando diz que ela "cria um mundo à sua imagem e semelhança". Desde o século XVI, com o declínio das estruturas feudais, o preconceito econômico-social, que tinha na religião a atenuadora das diferenças entre os homens (BUONICORE, 2009), no capitalismo, passa a ter a 'clivagem de classe' (MARX, 2007) como seu fundamento. 
Dessa forma, pode-se dizer que a relação capital-trabalho estabelece a primeira forma de preconceito econômico-social moderna: aquela que se trata da distinção de uma classe social em relação à outra (TAUSSIG, 1993). A lógica do acúmulo de capital, sustentada pela apropriação privada do produto do trabalho determina o desenvolvimento da desigualdade social (NUNES, 2006). No entanto, essa lógica não se limita apenas às condições materiais, mas se amplia às questões socioculturais, políticas e ideológicas, impactando nas representações sociais (IAMAMOTO, 1983).

No Brasil, há uma formação de estereótipos das classes dominantes que habitam as representações sociais e reiteram a existência do preconceito econômico-social. Esse preconceito emerge na própria formação social e econômica do Brasil, à medida que a história da sociedade brasileira é marcada por desigualdades econômicas, políticas, sociais e culturais, envolvendo classes sociais que reforçam o desprezo à 'questão social' (IANNI, 1992).

No Brasil, é comum a classe dominante expressar seu preconceito preferencialmente com o apelo às condições econômico-sociais como critérios de distinção (BANDEIRA, 2001). Esse critério se manifesta na construção do conhecimento e tem no ambiente educacional terreno fértil para a sua reprodução (ALTHUSSER, 1987).

As escolas, na sua maioria, legitimam a ideologia burguesa a membros de diferentes classes e, caso não sejam questionadas, são capazes de 'naturalizar' as relações de dominação (FRERES et al, 2008, p. 1-11). Nesse sentido, o preconceito econômico-social, por se ancorar na ideologia burguesa, é também reproduzido no ambiente escolar e serve para manutenção das relações de classe, à medida em que os objetivos da escola se circunscrevem a formar alunos para serem funcionais à estrutura hierárquica das corporações (BOWLES e GINTIS, 1976).

Ao se admitir, portanto, que a educação no sistema capitalista não visa eliminar as diferenças de classes, mas sim, perpetuá-las, é que se considera central a condição econômico-social na discussão do preconceito. 
Este preconceito é inculcado e acaba por se reproduzir no ambiente das universidades em todo o país (FRERES et al, 2008).

O debate sobre o preconceito econômico-social nas universidades públicas ganhou maior expressão com o avanço das ações afirmativas nos seus processos seletivos, em especial com uso do critério socioeconômico como parâmetro para o acesso ao ensino superior (MOREIRA et al, 2017, p. 89-98). Nesse sentido, parece pertinente tematizar as percepções sobre o conteúdo do 'preconceito econômico-social' nos estudantes, especialmente na educação das profissões da saúde, como é o caso da odontologia.

Mesmo considerando a existência de estudos que já investigaram outras expressões do preconceito (como a de gênero-sexualidade, por exemplo) em estudantes universitários (COSTA et al, 2015; BAUMGARTEN et al, 2017), outras expressões do preconceito como o racial, por exemplo (CABRAL, CALDAS JÚNIOR, CABRAL, 2005; SCHROEDER et al, 2017), e ainda, percepções de processos discriminatórios para criação de escalas (BASTOS et al, 2010); este estudo entende que a lacuna na construção do conhecimento científico reside na percepção do conteúdo sobre o 'preconceito econômico-social', ainda não tratado de forma focada pelos estudos anteriores.

Neste sentido, a disciplina de Ciências Sociais em Saúde da Faculdade de Odontologia da Universidade de São Paulo (FOUSP) propôs a reflexão sobre o 'preconceito econômico-social' nos seus ingressantes. A partir dessa prática pedagógica esse estudo se propõe a investigar a percepção dos graduandos de odontologia sobre este preconceito e sua relação com a saúde.

\section{Contexto pedagógico e percurso metodológico}

Este trabalho é parte de uma pesquisa pedagógica realizada na disciplina de Ciências Sociais em Saúde do curso de graduação em Odontologia da Faculdade de Odontologia da Universidade de São Paulo 
(FOUSP), Campus Capital. Do ponto de vista curricular, a disciplina se situa no primeiro ano do curso, sendo ofertada para os dois turnos (80 alunos no período integral e 50 no noturno), totalizando 130 estudantes.

Do ponto de vista do plano de disciplina, a mesma foi dividida por quatro módulos de aprendizagem, sendo o foco dessa pesquisa o segundo, intitulado "Saúde e Preconceito". Este módulo teve como objetivo refletir sobre as principais expressões sociais do preconceito (étnico, religioso, sexual, racial, político, cultural e econômico-social), sendo este último (o preconceito econômico-social) o recorte realizado por esta pesquisa.

No que se referiu à metodologia de ensino dos conteúdos da disciplina, foi utilizada uma mescla de métodos ativos de ensino-aprendizagem constituídos em: a) seminários - em que os grupos se expressavam livremente e de forma crítico-reflexiva sobre o tema proposto, incluindo dramatizações, músicas e outras estratégias pedagógicas e b) debates problematizadores como atividade-síntese. A avaliação se deu na modalidade 'processual' através da confecção de Cadernos Virtuais de Aprendizagem (CVA) ao longo de 4 meses. Os CVAs se constituíam de uma coleção de textos produzidos pelos estudantes no qual eles escreveram livremente seus pensamentos sobre o conhecimento produzido pela turma e por sua autorreflexão. Esse material foi divulgado no final do módulo no ambiente virtual da disciplina, localizado na plataforma Telessaúde/Teleodontologia da FOUSP.

Do ponto de vista da metodologia de pesquisa, tratou-se de um estudo híbrido (MEYER, 2009, p. 135-146), epistemologicamente filiado à matriz marxista (MARX, 2004), cujo marco conceitual foi a ideia de 'preconceito' nesta tradição. A partir de então, o objeto de estudo foi a percepção dos estudantes, alunos da disciplina acima citada, sobre o conteúdo do preconceito econômico-social e sua relação com a saúde através dessa matriz.

Assim, utilizou-se a pesquisa-ação, do tipo crítico-colaborativa (PIMENTA, 2005, p. 521-539), como método que fundamentou a produção 
das percepções sobre os conteúdos estudados. Tomou-se como 'ação' a produção coletiva das aulas expositivas-dialogadas pelos estudantes sobre o conteúdo do 'preconceito econômico-social' e sua relação com a saúde. Em adição, foi realizada a discussão e reflexão em sala de aula, através de 'tempestade de ideias' cuja digressão coletiva sobre o tema permitiu que os estudantes reelaborassem suas reflexões.

Em seguida, pediu-se para os estudantes registrarem suas reflexões realizadas sobre a 'ação' nos CVA. A intenção foi proporcionar a reestruturação e sistematização da percepção pela escrita. As produções destes CVAs podem ser caracterizadas na pesquisa educativa como 'textos produzidos pelos sujeitos' (BOGDAN e BIKLEN, 1998, p. 176-182) usados como documentos nos quais os estudantes foram avaliados através da 'devolutiva' e 'arbitragem' do professor sobre o conteúdo descrito, sendo este o segundo momento da 'ação'.

Desse modo, considerou-se na pesquisa apenas os estudantes que consentiram a análise de seus CVAs, totalizando 91 cadernos analisados. Os conteúdos foram sistematizados através da Análise de Conteúdo Clássica (BAUER, 2000). Nos CVAs, estava presente a percepção dos estudantes sobre o conteúdo de todos os tipos de preconceitos trabalhados na metodologia de ensino, no entanto, foram retirados dos textos aqueles corpus relativos apenas ao conteúdo relacionado ao 'preconceito econômico-social'. Os cadernos foram lidos na íntegra e em conjunto por seis analistas de conteúdo, em reuniões periódicas durante seis meses garantindo assim a validação interna (FLICK, 2009, p. 143-16) da análise.

Optou-se por tomar como Unidade Textual de Análise (UTA) as sentenças (frases, orações subordinadas e proposições) relativas à percepção sobre o conteúdo acerca do preconceito econômico-social escrito pelos estudantes com o intuito de não perder o foco. Em seguida essas sentenças foram classificadas por semelhança léxico-semântica em categorias que foram produzidas a partir da impregnação do texto pelos pesquisadores. 
Por fim, as categorias construídas serviram de elemento para compreender o espectro da percepção dos estudantes sobre o conteúdo do 'preconceito econômico-social' e sua relação com a saúde. A partir daí, foi realizada uma aproximação interpretativa de cunho marxista sobre o conteúdo deste 'preconceito' na relação de ensino-aprendizagem.

Este estudo não pretendeu inferir percepções de estudantes de odontologia de forma generalizada para além do grupo estudado ou, ainda, individualizando suas percepções em função das suas histórias pessoais. Tomou-se, portanto, como critério de homogeneidade fundamental (TURATO, 2003) o fato destes estudantes serem ingressantes nesta graduação e não terem passado pelo processo de biomedicalização característico do currículo odontológico. Além disso, não teve como intuito traçar um perfil dos estudantes a fim de cotejar sua percepção sobre o preconceito econômico-social em função da sua posição de classe. Este estudo se restringe a análise da percepção do conteúdo do preconceito econômicosocial e a saúde a partir da proposta pedagógica da disciplina.

Essa pesquisa foi aprovada pelo Comitê de Ética em Pesquisa (CEP) da Universidade de São Paulo, com o CAEE número 68743917.7.0000.0075. Para manutenção da confidencialidade os estudantes foram identificados por códigos alfanuméricos.

\section{Resultados e discussão}

De acordo como os textos produzidos pelos estudantes na disciplina, foi possível identificar 73 proposições (unidades de texto) que demonstram suas percepções sobre a relação entre preconceito econômico-social e saúde. Estas foram agrupadas em 18 categorias construídas ao longo do processo de análise e que demonstram, inicialmente, como se distribui a percepção dos estudantes sobre a temática. 
Tabela 1. Categorias relacionadas aos conteúdos identificados nos textos dos estudantes do $1^{\circ}$. ano de odontologia da FOUSP sobre a relação preconceito econômico-social e saúde. São Paulo, 2016.

\begin{tabular}{|c|c|c|c|}
\hline $\begin{array}{l}\text { Número } \\
\text { das } \\
\text { Categorias }\end{array}$ & Categorias & $\mathrm{N}$ & $\%$ \\
\hline 1 & $\begin{array}{l}\text { Existe a visão de que todos moradores de } \\
\text { rua são marginalizados pela sociedade }\end{array}$ & 7 & 9,6 \\
\hline 2 & Nós mesmos temos preconceitos & 7 & 9,6 \\
\hline 3 & $\begin{array}{l}\text { Uma forma de preconceito é aquela baseada } \\
\text { na imagem que temos das pessoas }\end{array}$ & 3 & 4,1 \\
\hline 4 & $\begin{array}{l}\text { Tanto ricos como pobres nutrem/sofrem os } \\
\text { preconceitos }\end{array}$ & 3 & 4,1 \\
\hline 5 & $\begin{array}{l}\text { Os preconceitos socioeconômicos e racial } \\
\text { estão conectados }\end{array}$ & 8 & 11,0 \\
\hline 6 & $\begin{array}{l}\text { Os preconceitos racial e socioeconômico } \\
\text { possuem origens históricas }\end{array}$ & 5 & 6,9 \\
\hline 7 & $\begin{array}{l}\text { A desigualdade social é palco para } \\
\text { preconceitos }\end{array}$ & 7 & 9,6 \\
\hline 8 & $\begin{array}{l}\text { A gente só quebra o preconceito quando } \\
\text { aprende a olhar com os olhos do outro }\end{array}$ & 1 & 1,4 \\
\hline 9 & $\begin{array}{l}\text { As doenças, independente de qual lado } \\
\text { atingem, são motivos de estigmas e } \\
\text { preconceitos }\end{array}$ & 10 & 13,7 \\
\hline 10 & $\begin{array}{l}\text { Somos iguais e é preciso combater esse } \\
\text { câncer da sociedade }\end{array}$ & 2 & 2,7 \\
\hline 11 & $\begin{array}{l}\text { O sistema capitalista molda a sociedade } \\
\text { para viver numa constante luta de classes e } \\
\text { determina a diferença social }\end{array}$ & 4 & 5,4 \\
\hline 12 & $\begin{array}{l}\text { É preciso vencer a segregação e acolher o } \\
\text { diferente }\end{array}$ & 3 & 4,1 \\
\hline 13 & $\begin{array}{l}\text { Os mecanismos de poder estão ligados ao } \\
\text { preconceito }\end{array}$ & 3 & 4,1 \\
\hline 14 & $\begin{array}{l}\text { As pessoas costumam não enxergar as } \\
\text { pessoas mais pobres. Enxergam-nas como } \\
\text { mendigos, lixeiros, faxineiras... passam na } \\
\text { sua frente e nem olham no rosto }\end{array}$ & 3 & 4,1 \\
\hline 15 & $\begin{array}{l}\text { É notável que grupos sob desvantagem } \\
\text { social recebem menos pelos mesmos cargos }\end{array}$ & 2 & 2,7 \\
\hline 16 & $\begin{array}{l}\text { O pré-conceito não é um conceito anterior ao } \\
\text { conhecimento }\end{array}$ & 1 & 1,4 \\
\hline 17 & $\begin{array}{l}\text { O preconceito se volta ao "pobre favelado" } \\
\text { visto como ameaçador }\end{array}$ & 3 & 4,1 \\
\hline \multirow[t]{2}{*}{18} & O preconceito contra o nordestino & 1 & 1,4 \\
\hline & TOTAL & 73 & 100,0 \\
\hline
\end{tabular}


Dentre as categorias mais frequentes, aquela referente às "doenças, independente de qual lado atingem, são motivos de estigmas e preconceitos" apresentou dez (10) proposições, representando $13,7 \%$ do total das proposições. Uma das percepções mais significativas apontava que:

[...] as doenças [...] independente de qual lado atingem são motivos de estigmas, de preconceitos. As pessoas, que são aquele 'ponto fora da curva', sempre são motivos de medo, e quase sempre são excluídas pela sociedade... [...]. Mesmo os mais ricos, por mais que tenham mais acesso, de uma forma ou outra sofrem preconceito, nem que seja ser taxado de louco. (TL10)

Para os estudantes, as doenças podem ser percebidas como uma expressão da condição de classe. Contudo, a percepção que o inverso, ou seja, o modo de vida associado às classes sociais determina a aquisição de certas doenças não parece tão claro. Este fenômeno, já descrito por Engels (2008, p. 67-76) em 1826, confirmava como o capitalismo produz doenças em função das relações de classe no mundo do trabalho. Contudo, no conteúdo expresso pelos estudantes, o foco na doença tende a inverter essa percepção.

Outra percepção reforça o argumento anterior. Por exemplo:

[...] as ideias de contágio, como o consumo de bebidas e a libertinagem ainda são enraizadas na sociedade e relacionadas às classes pobres... possuir tuberculose representa o declínio da vida de um indivíduo, devido ao estigma e ser uma doença presente somente em pobres e miseráveis. (R15)

Existe nos estudantes a percepção de que certos hábitos são moralmente condenáveis e, portanto, geradores de doenças. Essas doenças representam condições desfavoráveis 'do indivíduo' e, em certa medida, reforçam a etiologia biológica em detrimento da determinação social. Breilh (2006, p. 191-218) já problematizava como a ideia de 'contágio'/'exposição' é 
uma elaboração intelectual fecunda para fragmentar a percepção de totalidade, colocando intencionalmente as 'variáveis biológicas' no mesmo nível hierárquico que as classes sociais.

A partir desse momento, houve um grande esforço dos estudantes em caracterizar a categoria 'pobre', considerada essencial ao debate. Baseadas em diversas caricaturas da pobreza, as seis categorias seguintes se encarregaram desta delimitação.

A categoria que aponta que "os preconceitos socioeconômico e racial estão conectados" com oito (8) proposições e representando 11\%, inicia o processo. As percepções mais significativas dessa categoria apontavam que:

Esse tipo de preconceito é ainda muito presente atualmente, no entanto há ainda uma combinação de preconceito econômico-social com o racial. [...] ... há a ideia de que o negro rico não é bem visto pela sociedade em comparação com um branco pobre ou ainda com um negro pobre. (T13)

Sem dúvidas o preconceito mais abrangente no Brasil é o racial e este é ligado ao preconceito socioeconômico, uma vez que a organização social do Brasil é piramidal, em que o ápice é composto por ricos - que em sua maioria é constituído de brancose sua base, composta por pobres - que em sua maioria é formada por negros ou indígenas. (E7)

Esta categoria se relaciona com aquela em que os estudantes apontam que "os preconceitos racial e socioeconômico possuem origens históricas". Com 6,9\% (5) das proposições, as percepções sobre a mescla entre preconceito econômico-social e racial são percebidas assim:

Existem vários tipos de preconceitos, o racial pode ser relacionado com o socioeconômico, principalmente no Brasil onde 
historicamente os homens brancos tinham poder e os negros eram escravizados e subordinados a partir da força de trabalho. (TL1)

[...] esse tipo de preconceito foi utilizado na história como uma justificativa ao domínio de certos povos por outros, ao genocídio de alguns grupos, e como justificativa à escravidão. (R15)

Nessas categorias, o contexto histórico de escravidão e suas relações de poder estabelecidas se relacionam com a condição do negro no Brasil. Ianni (2004) demonstra que o país se apresenta impregnado por 'vários passados' e que a escravidão é o que mais marcou a constituição da 'condição de classe' brasileira.

Neste sentido, esperar certa sobreposição entre as opressões (BENSAÏD, LÖWY, 2017) 'ser negro' e 'ser pobre', opera uma representação para com a questão racial não somente biológica, que transcende a perspectiva biomédica (LOPES, 1997, p. 245-256). Neste bojo, os estudantes conseguem distinguir o peso das opressões classe-raça/cor na imagem: 'ser branco e pobre', apresenta um 'peso menor' que 'ser negro e rico'.

Outra categoria frequente foi aquela em que os estudantes admitiram que "existe a visão de que todos moradores de rua acabam sendo marginalizados pela sociedade”. Esta categoria apresentou sete (7) proposições representando $9,6 \%$ do total. Dentre as percepções mais significativas dessa categoria, esta aponta que:

Triste ver como o pobre, principalmente em situação de rua, ainda é marginalizado e tido como 'vagabundo', 'drogado', simplesmente pelo fato de não ter condições financeiras ou um emprego. (R3)

A imagem de "marginal" formada pelos estudantes parte de uma moralidade social construída a partir da representação do "marginal" como aquele que não se insere no sistema produtivo (ZALUAR, 1985). É 
recorrente nas unidades de texto a associação entre a falta de emprego e uso de drogas ilícitas à improdutividade. Estas incorporam um viés moral que situa a condição de classe a outras questões comportamentais, principalmente as geradoras de doenças.

Mais uma vez é o indivíduo, e não a situação de extrema pobreza, que o põe "à margem" (ZALUAR, 1985). A ausência de condições materiais de subsistência, inclusive, desperta nos estudantes a concepção de caridade. Nesse sentido, certa moralidade emerge no conteúdo ligando-se à compaixão.

A falta de condições de subsistência como a ausência de uma casa para morar denota os moldes higienistas da percepção dos estudantes da 'moradia como manutenção da vida privada' - a casa é privada (portanto, segura e salubre) e a rua é pública (insegura e insalubre) (GÓIS, 2002, p. 47 52). Concluindo a ideia de 'marginalização do indivíduo', é possível identificar sua 'invisibilidade', no sentido da perda de identidade do sujeito associada à improdutividade.

O grupo que abordou o tema deu bastante ênfase em mendigos, uma vez que é o exemplo mais claro de preconceito, não sabemos porque ele está ali, nem de onde ele veio nem quem ele é, no entanto, ele dificilmente é bem-vindo em algum lugar, tratado como um fantasma. (E12)

A categoria 'as pessoas costumam não enxergar as pessoas mais pobres. Enxergam-nas como mendigos, lixeiros, faxineiras... passam na sua frente e nem olham no rosto’ 4,1\% (3), ratifica a questão da invisibilidade.

As pessoas costumam não enxergar as pessoas mais pobres, como mendigos, lixeiros, faxineiras... passam na sua frente e nem olham no rosto. (CZ5) 
Associada a caricatura do 'pobre', a categoria 'O preconceito se volta ao "pobre favelado" visto como ameaçador' 4,1\% (3) reproduz a ideia higienista (de condições precárias como ameaça).

Mais uma vez o preconceito se volta ao 'pobre favelado', visto como ameaçador; enquanto na verdade, grande parte das pessoas que vivem sob condições precárias, são boas, honestas e trabalhadoras, merecedoras de respeito igual a um morador de um bairro nobre. (T8)

Por fim, 'o preconceito contra o nordestino' representando 1,4\% (1) do total de percepções, localiza a pobreza geograficamente. Uma 'invenção do nordeste' e do nordestino em termos de seu local de origem (como a seca, influências políticas e linguísticas), assumem uma imagem relacionada à pobreza e suas privações (ALBUQUERQUE JÚNIOR, 2007, p. 135).

Essas pessoas [grifo nosso] possuem dificuldade de arrumar emprego em São Paulo, já que as empresas dão uma aceitação melhor aos paulistas e também, são rotulados como burros, incompetentes, preguiçosos [...]. Parte desse preconceito, deve-se a posição financeira desfavorável, por ser uma região pobre e seca, apresentam diversos problemas consequentes na alimentação, educação, saúde, etc. (CZ6)

Em um momento de 'tomada de consciência', 9,6\% (7) das proposições descritas pelos estudantes admitiam que "nós mesmos nos pegamos tendo um preconceito". A percepção dos estudantes mais significativa descreve que:

[...] muitas vezes nós mesmos nos pegamos tendo um preconceito, por exemplo, quando um morador de rua pede dinheiro no semáforo, automaticamente assumimos a ideia de que ele vá usar o dinheiro para comprar drogas, sem sequer conhecê-lo, e isso é 
algo enraizado em nossa própria cultura e muitas vezes passadas pela nossa própria família. (LC7)

Os estudantes se surpreendem com os próprios preconceitos internalizados e os atribuem aos valores transmitidos por seus familiares. A moralidade transmitida é a relativa ao 'uso do dinheiro' para algo 'ilícito', ligado à sujeira, à imprevidência, ao impudor ou imprudência. Isso reforça a sobreposição entre o preconceito econômico-social com o preconceito com usuários de substâncias psicoativas, uma operação lógica típica de uma ética pequeno-burguesa (BOURDIEU, 1976).

Outra categoria expressiva foi aquela que atribuía “à desigualdade social como palco para este tipo de preconceito (econômico-social)” com a frequência de 9,6\% (7) das proposições. A percepção mais significativa descreve que:

[...] a desigualdade social é palco para este tipo de preconceito, em que a classe baixa passa por dificuldades com a educação precária, limitando-se assim o acesso a universidades públicas, a empregos bem remunerados, a programas culturais; além de uma saúde pública que não atende as necessidades da população, aumento da favelização, transporte público caótico, entre outros. (CZ12)

Os estudantes percebem a desigualdade social como central no debate sobre o preconceito econômico-social. Entretanto, a desigualdade não é tida como o 'foco gerador', suas consequências em termos de classes e condições de saúde-doença dependeriam, basicamente, do 'acesso às instituições' remetendo a uma perspectiva neocontratualista de 'igualdade de oportunidades' (RALWS, 1981).

Em termos marxianos, as instituições do Estado quando subsidiam questões sociais (como saúde, educação dentre outros), findam por favorecer sempre as frações de maior acesso aos bens materiais (MARX, 2012), já que o Estado e suas instituições tem imbricada relação com o capitalismo 
(CORREIA, 2015) e, neste modo de produção, a desigualdade social é estrutural.

Para alguns estudantes "o sistema capitalista molda a sociedade para viver numa constante luta de classes e determina essa diferença social" representando 5,4\% (4) do total de proposições.

Nessa categoria a 'classe social' aparece na percepção dos estudantes como fundamento da 'sociabilidade da diferença'. Baudelot e Establet (1973) discorrem sobre como a escola capitalista reproduz a divisão de classe no seu próprio interior, equaliza os desiguais e reproduz o individualismo burguês, aspecto fundamental para "cimentar" as relações de exploração de classe. $\mathrm{Na}$ escola odontológica, este fenômeno que inicialmente é tácito, se tornará evidente na "natural" divisão (segundo as diferenças econômico-sociais) das turmas para o atendimento clínico.

Ainda, os estudantes percebem que "uma forma de preconceito é aquela baseada na imagem que temos das pessoas" representando 4,1\% (3) do total de proposições.

As vestimentas são outro exemplo, pois elas influenciam na imagem que temos das pessoas. Enquanto julgarmos o caráter de alguém pela sua renda, por onde ela vive ou por como ela se veste, vamos continuar alimentando esse preconceito que é a razão de tanta discriminação. (T11)

As roupas traduzem e reafirmam uma imagem de distinção de classes. Associadas com a renda e ao poder de compra, estes símbolos servem de marcadores para uma 'economia da estética de classe'. O consumo conspícuo, que consiste na adoção de certos padrões cada vez mais custosos (FILHO, 2016, p. 223-251) é típico do cenário odontológico e muitas vezes incentivado por seus docentes. Isso reproduz a ideia de que 'tanto ricos como pobres nutrem/sofrem os preconceitos', 4,1\% (3). Para os estudantes: 
[...] tanto ricos como pobres nutrem esse preconceito, uma vez que não há interesse em ambos os lados de derrubar o muro que os separa, pois da mesma forma que tal muro garante 'segurança' para ricos, ele também garante 'poder' para aqueles que se beneficiam do tráfico de drogas por exemplo. (E5)

Aqui a naturalização é evidente. As ideias de 'rico' e 'pobre' não são compatíveis com a percepção de classe social. O preconceito, reiterado no 'discurso da igualdade', é tomado como um fenômeno que se expressa com todos de forma 'una' e reduzida a uma questão de um 'poder' genérico (BANDEIRA, 2001, p. 119-141), como se fosse possível apenas quebrar esse ‘muro' do poder para superar o preconceito econômico-social. Essa visão do 'poder' pode ser confirmada quando os estudantes apontam que 'os mecanismos de poder estão muito ligados ao preconceito’ 4,1\% (3):

Os mecanismos de poder estão muito ligados ao preconceito: não é à toa que eles existem, eles estão à serviço da economia. (E8)

Esta percepção sobre o fenômeno assinala a subsunção do poder 'genérico' à economia. O argumento retoma à ideia do 'político' como desvinculado ao 'econômico' (e ‘abaixo' dele), artifício bastante eficiente na domesticação da luta de classe (WOOD, 2004).

Em uma perspectiva de tentar superar o preconceito, alguns estudantes apontaram que 'é preciso vencer a segregação e acolher o diferente' $4,1 \%(3)$.

Fala-se também muito a respeito da inclusão... [...]. Por vezes, preconceitos revelam-se quebrados, todavia estão apenas sob um véu de aceitação social forçada. (E11) 
Os estudantes percebem que a ideia de 'inclusão' soa como um 'preconceito velado': as pessoas negam o preconceito, mas ele existe nas falas e atitudes. Nesse sentido, Ianni (2004, p. 8-20) ratifica a ideia de que formas de 'inclusão' são sempre concessões institucionais que reforçam a ordem. A ideia de acolhimento, por mais que seja bem-vinda, não é o suficiente para a superação da questão, como identificado pelo estudante.

Ainda na perspectiva propositiva, os estudantes encaminham a questão a partir da alteridade: 'a gente só quebra quando aprende a olhar com os olhos do outro' $1,4 \%$ (1).

[...] então, é um preconceito horrível que a gente só quebra quando aprende a olhar com os olhos do outro. (TL6)

E tentam escapar do senso comum na discussão quando afirmam que 'o pré-conceito não é um conceito anterior ao conhecimento' 1,4\% (1).

[...] porém, no meu ponto de vista, a definição 'pré-conceito' não é o que acontece realmente, o preconceito econômico e social afeta questões de trabalho, relacionamento, acesso à serviços e oportunidades, entre tantas outras problemáticas atuais, não sendo só um conceito anterior ao conhecimento. (T13)

Os estudantes afirmam ainda que é notável que grupos sob desvantagem social recebem menos pelos mesmos cargos' 2,7\% (2), demonstrando o esforço que fazem para emergirem do senso comum em direção a uma perspectiva mais refletida. Em suas percepções, o preconceito econômico-social se sobrepõe a questão da 'mulher' e demonstra a exploração do trabalho feminino.

Apesar das atenções estarem mais voltadas aos acontecimentos mais marcantes também é notável que as mulheres recebem menos pelos mesmos cargos, e também algo conhecido como 'pink 
tax' que encarece qualquer produto voltado ao público feminino. (CZ8)

Contudo, a metaforização biomédica (OLIVEIRA, 2002, p. 63-74), apesar de residual, ainda persiste. A percepção de que todos 'somos iguais e é preciso combater esse câncer da sociedade' 2,7\% (2) demonstra bem a argumentação fundamentada na 'igualdade' biológica, deslegitimando as razões sociais.

Como não se reconhecer em alguém que nasceu da mesma forma que você - pelado e chorando - e que, ao morrer, ficará da mesma forma que você. A realidade é que somos iguais e que é preciso combater esse câncer da sociedade. (TL6)

Apesar das percepções dos estudantes demonstrarem diversas interpretações sobre o tema em tela, é fundamental explicitar as limitações e as possibilidades em que esse processo pedagógico se desenvolveu, para que se possa compreender os resultados.

No que se refere às limitações, é possível dizer que estudantes de odontologia apresentam certa 'repulsa' pela discussão sobre 'o social', podendo muitas vezes elaborar textos apressados, pouco reflexivos e que não expressem suas verdadeiras percepções sobre o preconceito econômico-social, já que o material analisado faz parte do processo de avaliação final da disciplina.

No que tange as possibilidades, é possível dizer que seus resultados expressam o que há de mais genuíno na percepção de estudantes de odontologia em formação, já que os estudantes participantes não passaram pelo processo de biomedicalização do pensamento massivamente predominante no curso.

Além disso, o processo de análise pode ser considerado um ponto virtuoso desse estudo. Contando com seis analistas de conteúdo, analisando concomitantemente o mesmo material proporcionou uma pluralidade de 
compreensões sobre 'o texto' e 'o contexto' produzindo uma análise com uma validade considerável.

Em termos gerais é possível afirmar que o processo pedagógico ampliou as percepções dos estudantes sobre o assunto, fato que não aconteceria caso não houvesse disciplinas com o enfoque nas ciências sociais. A tendência, muito comum em diversos currículos odontológicos é restringir, ainda mais, a visão biomédica centrada na doença. Daí a justificativa inconteste da necessidade dos conteúdos sociais e humanísticos nos cursos de graduação em odontologia, reforçando as recomendações das diretrizes curriculares nacionais para cursos de graduação em odontologia (BRASIL, 2002, p. 10).

Por fim, pode-se dizer que a adoção de uma estratégia de ensinoaprendizagem centrada em metodologias ativas de problematização, bem como o exercício da livre escrita crítico-reflexiva nos CVAs propiciaram um ambiente favorável aos estudantes e garantiu à expressão mais próxima de suas vivências e percepções.

\section{Considerações finais}

A boniteza do 'ensinar e aprender' se caracteriza pela capacidade dos sujeitos em realizarem uma construção social do mundo mais autônoma e menos refém das estruturas, das instituições e de sua própria história (FREIRE, 1996).

Neste sentido, este foi um exercício pedagógico que exigiu esforço dos estudantes em saírem do senso comum para edificarem um pensamento social sobre o preconceito econômico-social de forma mais ampla, seus rebatimentos na saúde dos indivíduos, e, sobre si mesmos.

Assim, é possível dizer que o espectro da percepção dos estudantes sobre o preconceito econômico-social e sua relação com a saúde é dotada de uma pluralidade essencialmente contraditória de pelo menos quatro matizes. 
Um deles pode ser considerado como 'substrato da reprodução do preconceito econômico-social' que se assenta na persistência expressiva da visão biomédica da doença como determinadora do social, na percepção de certos hábitos considerados moralmente condenáveis, nas ideias de 'rico' e 'pobre' como sinônimo de classe social, na desigualdade que não é tida como o 'foco gerador' do preconceito e na ideia do poder como algo desvinculado do econômico.

O outro matiz pretendeu uma 'passagem da reprodução para a crítica' que pode ser entendida na percepção sobre a distinção do peso das opressões classe-raça/cor e gênero, na percepção da desigualdade social como centro do debate sobre o preconceito econômico-social, na consideração da 'classe social' como fundamento da sociabilidade, e no próprio preconceito vivido e a falácia da ideia de 'inclusão'.

Contudo, um exame autocrítico deve ser feito sobre o aspecto que expõe o 'preconceito internalizado dos próprios estudantes'. As ideias caricatas de pobreza reduzidas à marginalidade, à ameaça, associadas à caridade, ao higienismo, à invisibilidade desqualificam o debate. $\mathrm{O}$ uso moral do dinheiro e a economia estética de uma classe se agregam à 'invenção do nordeste' na tentativa delimitar ideais que, muitas vezes, não correspondem às condições objetivas e reforçam a reprodução.

$\mathrm{O}$ último matiz se referiu às 'soluções propostas' pelos estudantes que encaminham soluções a partir da alteridade e de metáforas biomédicas da sociedade que, certamente, pouco contribuem para compreender e enfrentar o fenômeno do preconceito econômico-social em sua totalidade.

Entendemos, que o ensinar-aprender conteúdos sociais e humanísticos nas graduações em saúde é um verdadeiro "canteiro de obras", inacabado! Quem ensina esses conteúdos, em especial na matriz crítica deve ter como obrigação o ensino como uma ferramenta de mudança da ordem social; ordem esta, que, por si só, já é uma fábrica de preconceitos.

\section{Referências}


ALBUQUERQUE JÚNIOR, D. M. Preconceito contra a origem geográfica e de lugar - As fronteiras da discórdia. 1. ed. São Paulo: Cortez, 2007. 135p.

ALTHUSSER, L. Aparelhos Ideológicos de Estado. $3^{\text {a }}$ edição. Rio de Janeiro: Edições Graal, 1991.

BANDEIRA, L.; SORIA, A. B. Preconceito e discriminação como expressões de violência. Revista Estudos Feministas, Florianópolis, v. 10, n. 1, p. 119-141, 2001.

BASTOS, J. L. et al. Experiências de discriminação entre universitários do Rio de Janeiro. Rev. Saúde Pública, São Paulo, v. 44, n. 1, fev. 2010.

BAUDELOT, C.; ESTABLET, R. La escuela capitalista. México: Siglo Veintiuno, 1975.

BAUMGARTEN, A. et al. Discrimination, gender and self-reported aesthetic problems among brazilian adults. Community Dent Oral Epidemiol, Porto Alegre, v. 46, n. 1, p. 24-29, fev. 2017.

BENSAÏD, D.; LÖWY, M. Centelhas. São Paulo: Boitempo, 2017.

BOGDAN, R.; BIKLEN, S. Investigação qualitativa em Educação: fundamentos, métodos e técnicas. In: Investigação qualitativa em educação. Portugal: Porto Editora, 1994, p. 176-182.

BOWLES, S.; GINTIS, H. Schooling in capitalist America. 1. Ed. Nova Iorque: Basic Books, 1977.

BRASIL. Ministério da Educação. Resolução n CNE/CES 3/2002 de 19 de fevereiro de 2002. Institui as Diretrizes Curriculares Nacionais dos Cursos de Farmácia e Odontologia. Diário Oficial, Brasília, 04 mar. 2002, seção 1, p. 10.

BREILH, J. Da Epidemiologia Linear à Epidemiologia Dialética. In: BREILH, J. Epidemiologia crítica: ciência emancipadora e interculturalidade. Rio de Janeiro: Fiocruz, 2006. p. 191-218.

BUONICORE, A. C. Marxismo, história e revolução brasileira: encontros e desencontros. In: São Paulo: Anita Garibaldi, 2009.

CABRAL, E. D.; CALDAS JÚNIOR, A F.; CABRAL, H. A. M. Influence of the patient's race on the dentist's decision to extract or retain a decayed tooth. Community Dentistry and Oral Epidemiology, Recife, v. 33, n. 6, p. 461-466, out. 2005.

CORREIA, M. O. G. Por uma crítica imanente sobre os limites das políticas públicas de direitos sociais e o Estado na produção do bem comum no modo de produção capitalista. Saúde e sociedade, São Paulo, v. 24, supl. 1, p. 55-65, 2015. 
COSTA, A. B. et al. Prejudice toward gender and sexual diversity in a brazilian public university: prevalence, awareness, and the effects of education. Sexuality Research and Social Policy, Porto Alegre, v. 12, n. 4, p. 261-272, dez. 2015.

ENGELS, F. As Grandes Cidades. In: ENGELS, F. A situação da classe trabalhadora na Inglaterra. São Paulo: Boitempo, 2008. p. 67-76.

FLICK, U. Utilização de documentos como dado. In: Introdução a pesquisa qualitativa. 3. ed. São Paulo: Editora Artmed, 2009, pp.143-166.

FREIRE, P. Educação como prática da liberdade. 29. ed. Rio de Janeiro: Paz e Terra, 2006.

FRERES, H. A,; RABELO, J.; MENDES SEGUNDO, M. D. A função da educação no atual contexto histórico: uma análise onto-histórica. In: V Congresso Brasileiro de História da Educação: ensino e a pesquisa em história da educação. Anais do $V$ Congresso Brasileiro de História da Educação, Aracaju: 2008. p. 1-11.

GÓIS, E. Movimento Higienista na história da vida privada no Brasil: do homogêneo ao heterogêneo. ConScientiae Saúde, São Paulo, v. 6, n. 1, p. 47-52, 2002 .

IAMAMOTO, M. V.; CARVALHO, R. Relações Sociais e Serviço Social no Brasil: esboço de uma interpretação histórico-metodológica. 1. Ed. São Paulo: Cortez, 1983.

IANNI, O. A ideia de Brasil Moderno. São Paulo: Editora brasiliense, 1992.

Octávio Ianni: o preconceito racial no Brasil. Estudos Avançados, São Paulo, v. 18 n. 50 p. 8-20, 2004.

LOPES, A. A. Significado de Raça em Pesquisas Médicas e Epidemiológicas. In: BARATA, R. B.; BARRETO, M.L; ALMEIDA FILHO, N.; VERAS, R. P. (Orgs). Eqüidade e Saúde: Contribuições da Epidemiologia. Série Epidemiológica 1. Editora Fiocruz/ABRASCO. Rio de Janeiro, p. 245-256, 1997.

MARX, K. Crítica ao Programa de Gotha. São Paulo: Boitempo, 2012. Manuscritos econômico-filosóficos. São Paulo: Boitempo, 2004.

MARX, K.; ENGELS, F. O Manifesto Comunista. São Paulo: Boitempo, 2007. A ideologia alemã. São Paulo: Boitempo, 2007a.

MEYER, J. Pesquisa-ação. In: POPE, C; MAYS, N. Pesquisa qualitativa em saúde. 3. ed. Porto Alegre: Artmed, 2009, p. 135-146.

MOREIRA, G. O. et al. Inclusão social e ações afirmativas no ensino superior no Brasil: para quê?. Ensino Superior, Unicamp, Campinas - SP, Disponível em: $<$ https://www.revistaensinosuperior.gr.unicamp.br/artigos/inclusao-social-e-acoesafirmativas-no-ensino-superior-no-brasil-para-queij>. Acesso em: 08 mar., 2018. 
NUNES, S. S. Racismo no Brasil: tentativas de disfarce de uma violência explícita. Revista Psicologia USP, São Paulo, v. 17, n. 1, p. 89-98, 2006.

OLIVEIRA, F. A. Anthropology in healthcare services: integrality, culture and communication. Interface: Comunicação, Saúde, Educação, Botucatu, v.6, n.10, p.63-74, 2002.

PACHUKANIS, E. A teoria geral do direito e o marxismo e ensaios escolhidos (1921-1929). São Paulo: Sundermann, 2017.

PIMENTA, S. G. Pesquisa-ação crítico-colaborativa: construindo seu significado a partir de experiências com a formação docente. Educação e Pesquisa, São Paulo, v. 31, n. 3, p. 521-539, set./dez. 2005.

RAWLS, J. Uma teoria da Justiça. Tradução de Vamirch Chaeon. Brasília: Editora Universidade de Brasília, 1981.

SALES JÚNIOR, R. Democracia racial: o não-dito racista. Tempo Social - Revista de Sociologia da USP. São Paulo, v.18, n.2, p. 229-258, 2006.

SCHROEDER, F. C. et al. To extract or to restore the tooth? color/race and clinical decision making among undergraduate dental students from southern Brazil. Pesquisa brasileira em odontopediatria e clínica integrada, Paraíba, v. 17, n. 1, p. 1- 12, 2017.

TAUSSIG, M. Mimesis and Alterity. 1. Ed. Nova York: Routledge, 1993.

TEIXEIRA FILHO, F. L. E quando ser o que se é tornou-se uma fundada suspeita: elementos de uma estética de classe e do preconceito. Revista o público e o privado, Fortaleza, n. 28, p. 223-251, 2016.

TURATO, E. R. Tratado da metodologia da pesquisa clínico-qualitativa: construção teórico-epistemológica, discussão comparada e aplicação nas áreas da saúde e humana. Petrópolis: Vozes, 2003.

WOOD, E. M. Democracia contra o Capitalismo: a renovação do materialismo histórico. São Paulo: Boitempo, 2010.

ZALUAR, A. A máquina e a Revolta - As Organizações Populares e o Significado da Pobreza. São Paulo: Brasiliense, 1985.

ZANETTI, C. H. G. A formação do cirurgião-dentista. In: DIAS, Aldo Angelim. Saúde bucal coletiva - metodologia de trabalho e práticas. São Paulo: Editora Santos, 2007, p. 21-42. 